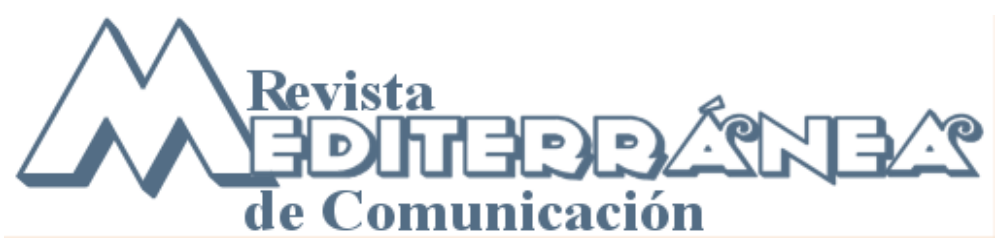

Año 3 (2012), pp. 1-13 ISSN 1989-872X

Fecha de recepción: 20/06/2011; Fecha de publicación: 01/06/2012

\title{
Elementos diferenciales en la forma audiovisual de los videojuegos. Vinculación, presencia e inmersión.
}

\section{Differential elements in the audiovisual form of the video games. Bonding, presence and immersion.}

\author{
Dr. José Manuel Pestano Rodríguez \\ Universidad de La Laguna - España \\ jpestano@ull.es \\ Dra. María Gabino Campos \\ Universidad Autónoma de San Luis Potosí - México \\ Dra. Patricia Delponti \\ Universidad de La Laguna - España
}

\section{Resumen}

En poco más de dos décadas los videojuegos alcanzan las primeras posiciones del sector audiovisual. Distintos hechos y factores técnicos, económicos y sociales hacen posible que los videojuegos sean en estos años la referencia de ocio para una cifra creciente de millones de personas. A este fenómeno contribuye también que sus creadores desarrollan relatos junto a elementos de interacción con el objetivo de conseguir una elevada inversión temporal por parte de los usuarios. Indagamos en los conceptos de vinculación, presencia e inmersión por sus implicaciones en el universo sensorial de los videojuegos y mostramos el estado en el que se encuentra la investigación audiovisual en este campo en la primera década del siglo XXI.

\section{Abstract}

In just over two decades the video games reach the top positions in the audiovisual sector. Different technical, economic and social facts make that video games are the main reference of entertainment for a growing number of millions. This phenomenon is also due to its creators develop stories with elements of interaction in order to achieve high investment of time by users. We investigate the concepts of bonding, presence and immersion for its implications in the sensory universe of video games and we show the state of the audiovisual research in this field in the first decade of the century.

Palabras claves

Video games; cultural industries; bonding; immersion; presence. 


\section{Key Words}

Bolivarian Republic of Venezuela; country image; country brand image; media; Spain; President Hugo Chávez; analysis of contents.

Sumario: 1. Introducción. 2. Metodología. 3. Datos y discusión. 3.1 Vinculación. 3.2 Inmersión. $\quad 3.3$ Presencia y flujo. 3.4 Conexiones entre inmersión y forma audiovisual. 4. Conclusiones. 5. Referencias.

Summary: 1. Introduction. 2. Methodology. 3. Discussion. 3.1 Bonding. 3.2 Immersion. 3.3 Presence and flux. 3.4 Connections between immersion and audiovisual form. 4. Conclusions. 5. References.

\section{Introducción}

A lo largo de la primera década del siglo XXI los videojuegos se revelan como objeto de estudio en las áreas de comunicación. Hasta hace unos años los autores que dedicaban algún trabajo a los videojuegos eran escasos (Arroyo, 1999; Garitaonandia et al., 1999; Moreno, 2003; Aguilera, 2003 y 2004), a veces en conexión con otras áreas próximas como la educación (De Aguilera y Méndiz, 2006; Gros, 1998). A partir de 2006 los videojuegos ganan presencia en la escena académica, y la riqueza del fenómeno sugiere que en los próximos años se dedicarán más investigaciones a sus problemas conceptuales y de estructura productiva (Checa, 2009; Martín, 2010; Rodríguez et al., 2011), así como a estudios comparados entre distintos medios (Pestano et al., 2010).

Abordamos aquí el estado de la investigación sobre varios elementos del videojuego, que no lo caracterizan exclusivamente ya que aparecen en otros medios, pero que se presentan en el videojuego con intensidad manifiesta. Por lo tanto el objetivo que planteamos es conocer el estado de la investigación en cuanto a los fenómenos de vinculación, inmersión y presencia en los videojuegos, su caracterización teórica y sus conexiones con la narrativa y la expresión de la forma audiovisual.

\section{Método}

En primer lugar establecemos una radiografía del estado de la investigación reciente realizada en España sobre videojuegos considerando su presencia en tesis doctorales y la publicación de trabajos en revistas científicas de comunicación. A continuación realizamos una exposición de los conceptos de vinculación, inmersión y presencia asociados a los videojuegos; como cierre planteamos posibles líneas de trabajo futuras alrededor del estudio de estos elementos y sus relaciones con la forma audiovisual, ya que características intrínsecas del videojuego como su narrativa, contribuyen notablemente en los estados de inmersión y presencia.

\section{Datos y discusión}

Desde 1996 encontramos 21 tesis doctorales que tienen relación con los videojuegos; se eligen aquellas en las que el tema de los videojuegos aparece como un elemento relevante en la tesis, aunque no sean el núcleo central de la misma. En la tabla 1 se recogen los campos científicos de los que proceden estos trabajos. 
Tabla 1: Tesis doctorales españolas según el área científica de procedencia.

\begin{tabular}{|l|l|l|l|l|l|l|l|l|l|l|l|l|l|l|l|l|l|}
\hline & 1996 & 1997 & 1998 & 1999 & 2000 & 2001 & 2002 & 2003 & 2004 & 2005 & 2006 & 2007 & 2008 & 2009 & 2010 & Total & $\%$ \\
\hline Psicología & 1 & 1 & & & 1 & & 2 & & & 1 & 1 & 1 & & & 1 & 9 & 42,86 \\
\hline Educación & & & 1 & & 1 & & & & 1 & & 1 & & & 2 & & 6 & 28,57 \\
\hline Informática & & & & & & & & & & & & 1 & 2 & & 1 & 4 & 19,05 \\
\hline Marketing & & & & & & & & & & & 1 & & & & & 1 & 4,76 \\
\hline Comunicación & & & & & & & & & & 1 & & & & & & 1 & 4,76 \\
\hline
\end{tabular}

Fuente: Elaboración propia a partir de datos de Teseo, Ministerio de Educación (2010)

También hemos visto la frecuencia de los términos 'videojuegos' e 'inmersión' en las revistas españolas de comunicación consideradas fuente por el índice INRECS. Hemos buscado en el título del artículo y en el resumen para determinar su relevancia. Ambas frecuencias son bajas: videojuegos $0,56 \%$ e inmersión $0,07 \%$.

Tabla 2: Aparición de artículos sobre 'videojuegos' e 'inmersión' en las revistas fuente de comunicación en el período 2005 - 2010.

\begin{tabular}{|l|l|l|l|}
\hline REVISTA & Número de artículos & 'Videojuegos' & 'Inmersión' \\
\hline Latina & 214 & $1(2008) 1(2009)$ & 0 \\
\hline Zer & 156 & $1(2010)$ & 0 \\
\hline Comunicación y Sociedad & 66 & 0 & 0 \\
\hline Análisi & 131 & 0 & 0 \\
\hline Comunicar & 473 & $1(2006) 1(2009)$ & 0 \\
\hline Estudios sobre el mensaje periodístico & 163 & $2(2010)$ & \\
\hline Telos & 223 & $1(2010)$ & 1 \\
\hline
\end{tabular}

Fuente: Elaboración propia.

En estos años dos revistas destacan por dedicar monográficos a los videojuegos. En 2004 la revista Icono14, de la Asociación Científica del mismo nombre y próxima al área de comunicación audiovisual y publicidad, será la primera en dedicar un número monográfico a los videojuegos; posteriormente repetirá la experiencia en 2006; en 2009 Comunicación. Revista Internacional de Comunicación Audiovisual, Publicidad y Estudios Culturales de la Universidad de Sevilla hará otro tanto.

Desde la psicología y la educación se realizan aportaciones con enfoques explicativos, transformadores y/o aplicados, adaptando los juegos existentes o creando nuevos que sean útiles para la enseñanza o el entrenamiento en diferentes contextos (Alexander, 2005; Gramigna y González-Faraco, 2009). La educación trata de aprovechar las experiencias que proporcionan los videojuegos para intentar abordar el principal reto educativo: la baja eficiencia de los sistemas educacionales que se manifiesta en las enormes dificultades con la que aprendemos los humanos cuando lo que tenemos que aprender no nos interesa, como oposición a la habilidad para aprender que tienen los jugadores cuando interaccionan con un juego que sí responde a sus intereses (Dondlinger, 2007; Ryan y Siegel, 2009); utilizando videojuegos específicos Rosas et al. (2003) no encuentran grandes avances en la adquisición de los contenidos por parte de los alumnos pero sí mejorías en cuanto a la motivación, eje principal sobre el que construir aprendizajes futuros. 
Para todos ellos, el tipo y las características del diálogo entre jugador y juego resultan determinantes para explicar por qué un jugador elige, juega y vuelve a jugar a un videojuego determinado. Existen múltiples aproximaciones a esta fuente motivacional que han sido tratada desde la posición de la industria (Klug y Schell, 2006: 104), la psicología evolutiva (Olher y Nieding, 2006: 115) o la teoría de usos y gratificaciones (Salish et al, 2006: 170), entre otras. Solo recientemente aparecen autores que tratan en castellano el término inmersión (Pestano y Gabino, 2010) y el conjunto conceptual inmersión, presencia y flujo (Armenteros y Fernández, 2010); estas características diferenciales de los videojuegos próximas a la inmersión, como vinculación, adicción, presencia y flujo contemplan fronteras y espacios de sentido comunes.

\subsection{Vinculación}

El primero de estos términos es la vinculación, que definimos como el conjunto de relaciones que unen jugador y juego. Los elementos característicos de la vinculación funcionan como un sistema interpenetrado, en el que existen todos los elementos que vamos a tratar a continuación, estableciendo entre ellos relaciones de interdependencia en las que no existe en todos los casos una hegemonía clara de unos elementos sobre el resto. La vinculación contiene elementos intrínsecos al juego, elementos comunes al juego y al jugador, y por último, los elementos situados en la esfera social del jugador.

Entre los elementos intrínsecos al juego aparecen los diegéticos propios de la narración, los elementos estéticos y los extradiegéticos como el espacio normativo. Entre los elementos intrínsecos encontramos las narrativas de los videojuegos. Resultan frecuentes productos que emplean narrativas lineales, próximas a la experiencia televisiva o a la cinematográfica, con estructura de collar de perlas, en las que cada fase tiene al final una meta que si se supera permite el acceso a la siguiente fase; generalmente, el usuario conoce la historia que recorre el juego, y si ésta le resulta atractiva añade un factor más de vinculación al juego (Sicart, 2007). Pero además se han desarrollado narrativas multilineales y arborescentes, junto a otras más o menos abiertas a la construcción de los jugadores, que incluso puede utilizar construcción colaborativa, como sucede en algunos videojuegos de rol masivos multijugador en línea, MMORPG, (Landwehr et al, 2009) que dan lugar a universos persistentes en los que el jugador siempre se encuentra acompañado (Sáez Soro, 2009). Probablemente, estas narrativas no lineales basadas en la interacción social inviten a jugar más veces a un juego que no es predecible con facilidad. En las narrativas lineales también se suele enriquecer el relato a lo largo del juego, incrementando el conocimiento de la historia mediante nuevos discursos paralelos o de refuerzo, que pueden utilizar distintas técnicas expresivas, desde las simples formas de textos sobreimpresionados, elaborados vídeos o misiones alternativas.

Las bases y reglas constituyen el espacio normativo de la ludodiégesis en el que se desenvuelve el jugador de un videojuego; aparentemente, las bases y reglas sencillas invitan a la participación espontánea, mientras que la existencia de normas ocultas o cambiantes puede disuadir a los jugadores menos interesados; en este espacio normativo también se incluyen los caminos más o menos explícitos para obtener el éxito, parcial o final; también existen saltos normativos en forma de trucos, instrucciones y trampas que permiten alcanzar el final sin seguir las normas convencionales. En algunos videojuegos simples, como los arcades que se basan en 'disparar primero' o en los de carreras, bases y reglas son muy sencillas, mientras otros videojuegos de enorme aceptación y larga historia, como Pokemon (1996), exigen un conocimiento avanzado de las características de los personajes y de las consecuencias de su interacción. 
Los elementos estéticos ocupan una posición relativa en el desarrollo de la vinculación de un jugador a un juego, aunque sus implicaciones se han comenzado a estudiar hace poco (Aarseth, 2007) por medio de métodos específicos para el análisis de videojuegos. Decimos que se trata de una posición relativa porque estéticas y narrativas simples han contribuido poderosamente en el proceso de vinculación, motivación y elección de un videojuego, mientras que otras más complejas no lo han conseguido. Sí encontramos un constante esfuerzo por unir estética y tecnología, lo que se aprecia en las actuaciones de la industria dirigidas a producir entornos cada vez más adaptados a la percepción humana, empleando sonidos e imágenes altamente elaborados; pero también sabemos de productos que alcanzaron un alto grado de vinculación y que carecieron, o que carecen, de elevados estándares tecnológicos, y que sin embargo se convierten en referencias culturales entre los jugadores, como ocurrió con World of Warcraft (2004), en el que la presentación visual no era su principal atractivo. De hecho algunos juegos de aventuras basan en los cambios estéticos su éxito y renovación a partir de cadenas de situaciones fácilmente predecibles. Las decisiones respecto a cuestiones como punto de vista, perspectiva o grado de realismo tendrán consecuencias en el dominio de la vinculación.

Respecto a los elementos comunes al juego y al jugador indicamos ahora sólo la 'conversación' que se establece entre jugador y juego, fundamentada en la interactividad; esta 'conversación' también es acción en un universo, el del juego, el que las acciones tienen consecuencias. Esta interacción puede basarse en el binomio individuo - software, o puede ser una interacción más social; de esta última deberíamos distinguir en la interacción con un agente informático, un avatar de la máquina que interactúa con el jugador y la interacción plenamente social, que lleva a cabo el jugador con otros jugadores humanos.

Entre los elementos que facilitan la vinculación al juego desde la perspectiva del jugador algunos son individuales, como sus conceptos previos e informaciones procesadas; otros tecnológicos, derivados de los equipos que se utilizan para jugar, y también pueden ser sociales, como el entorno social de juego, entorno social refractario al juego y contexto informacional compartido.

El vínculo que establece un jugador y el juego puede llegar a producir adicción puesto que de las circunstancias del juego se derivan situaciones placenteras que no encuentran sustituto. Parece necesario distinguir entre distintos estados adictivos hasta llegar a la adicción patológica, en la que no le resulta posible a la persona prescindir de la actividad lúdica (Castellana et al., 2007). A diferencia de lo que ocurre con otros tipos de juegos, en los que la adicción es un tabú que no se menciona, en el caso de los videojuegos constituye un término de referencia en su marketing, ofreciendo la adicción como un atributo positivo del producto, de interés para el jugador. La vinculación contribuye a crear, desarrollar y fortalecer la inmersión en el mismo.

\subsection{Inmersión}

El interés que el término inmersión suscita en el campo de los videojuegos ha servido para motivar la investigación académica desde posiciones próximas a nosotros. En España existen alrededor de treinta revistas de comunicación; revisando esta literatura específica en torno al concepto de 'inmersión' asociado a 'videojuegos', encontramos una primera referencia a este elemento característico de la experiencia de juego en Marcos y Martínez (2006). 


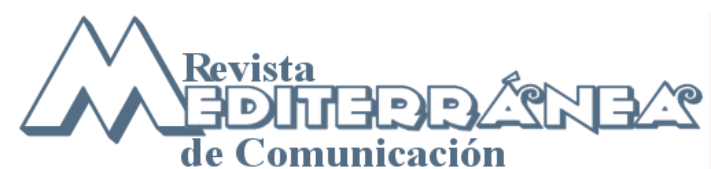

ISSN 1989-872X - Año3 (2012), pp. 1-13

Para tratar la noción de inmersión podemos comparar dos situaciones diferentes: la del usuario de un videojuego y la de lector ante un libro; en ambos casos se supone interés por parte del usuario. En el caso de la lectura nos encontramos ante un proceso cognitivo en el que el lector se sumerge en un entorno, negociando con el texto los significados del relato. Un estado de concentración perceptiva variable aparece con frecuencia en la lectura, en particular cuando la diégesis atrapa al lector y además, éste tiene sus competencias lectoras desarrolladas adecuadamente.

Podemos observar esa concentración perceptiva en otros juegos sin apenas componente narrativa como puede ser el ajedrez. Cuando alguien juega con cierto nivel al ajedrez la mente se concentra en el tablero y en la distribución de las piezas, y el jugador emplea su capacidad cognitiva para evaluar la propia estrategia frente a la del adversario con el objetivo de encadenar unas series de movimientos que le den ventaja o victoria. El universo perceptivo se comprime hasta ubicarse en el tablero; poco queda más allá del cronómetro o de la mesa en la que se disputa la partida. Se trata de un proceso que prescinde del mundo real no relevante, en este caso el juego, y que realizan voluntariamente los jugadores porque les produce determinadas sensaciones entre las que podemos citar la excitación del juego y el placer de la competición.

Al igual que en el caso de la lectura, la tecnología utilizada en el ajedrez no tiene que ser digital y electrónica, sino analógica y sencilla, unas piezas, un tablero y poco más. Pero el proceso concentración de la realidad sobre el tablero nos informa de la necesidad que tiene el jugador de emplear todos sus recursos sensoriales y mentales en la tarea que le ocupa; un jugador aventajado puede jugar simultáneas, un término relativamente afortunado para designar el juego de un solo jugador contra varios jugadores, a veces decenas o cientos; en este caso, el proceso de concentración-desconcentración es inmediato, de un tablero a otro, un golpe de vista y de mente que producen una jugada, y a otro tablero. Nos encontramos ante un proceso en el que se prescinde de lo irrelevante del entorno para utilizar el máximo de actividad mental en un sentido unívoco. En este caso el jugador atiende al juego, pero no forma parte del juego, no se percibe a sí mismo como parte del tablero, no adopta la forma de las piezas y la interacción social que se produce es poca, ya que hablar al oponente mientras se juega no suele ser aceptable, por lo menos en competición. A este proceso podemos denominarlo concentración perceptiva.

Tanto la práctica de la lectura como la del juego del ajedrez pueden suponer formas de inmersión, aunque de distinto tipo; probablemente la práctica del ajedrez sea más reflexiva y distante, propia de la concentración perceptiva, y la lectura pueda conducir a una inmersión más irreflexiva, próxima e inevitable. Ambas realizan operaciones de reducción perceptiva sobre el sujeto, como ocurre cuando privamos al receptor de otros estímulos que no sean aquellos que queremos utilizar para vehicular nuestro mensaje; no queremos entrar en la discusión espectador pasivo o activo, no será necesario, porque en la reducción perceptiva no incluimos la reducción de actividad mental, lo que se produce es una conducción de todos los recursos disponibles en una misma dirección. En el ámbito de la forma audiovisual este fenómeno resulta frecuente, a diferencia de lo que ocurre con otras artes tradicionales, en las que el espectador recibe sin formar parte del universo de la obra (Siabra, 2009). Por ejemplo, en la sala de cine, oscurecido el entorno y fuertemente iluminada la pantalla utilizamos la proyección de imágenes y la reproducción multicanal de sonidos a un volumen, por lo general elevado, para situar a nuestra merced al espectador, que asiste al espectáculo audiovisual que se desarrolla a partir de una narración lineal, sin que las posibles acciones del espectador tengan ninguna influencia en el relato expuesto, pero sin 


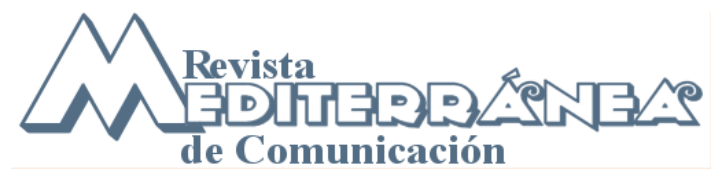

ISSN 1989-872X - Año3 (2012), pp. 1-13

negar que existe una considerable actividad, mental, por parte del sujeto y ante determinados contenidos.

Díez Gutiérrez (2004) expone como la experiencia directa con jugadoras y jugadores informa de distintos grados de interconexión de los sujetos con el juego; en el siguiente texto registra la observación de una jugadora a la que se está entrevistando mientras juega y que muestra signos de concentración, presencia e inmersión; la jugadora desconecta del mundo que la rodea, se sumerge en el juego, y en ese proceso se revela su estado en el mundo virtual materializado a través de su cuerpo:

\begin{abstract}
"Se calla aquí. Ha llegado a una zona conflictiva y se ha encontrado con un adversario. La jugadora se pone expectante cuando el personaje acecha a un enemigo, no sólo mueve el joystick sino también el cuerpo. Se mueve con el personaje. El personaje principal resulta eliminado en este encuentro. El rival lo aplasta con una maza. El indicador es un destello rojo que simula sangre aunque no son las tradicionales manchas" (Díez Gutiérrez, 2004: 301)
\end{abstract}

Parece necesario otorgar a la inmersión grados variables que dependen del objeto que provoca la situación, del sujeto y de la relación que se establece entre ambos; a su vez esta malla de estímulos y relaciones también depende de otras circunstancias, de forma que no siempre los mismos factores producen el mismo efecto.

El concepto de inmersión aparece en la lingüística, definido en primer lugar como acción de introducir o introducirse algo en un fluido", en segunda acepción como "acción de introducir o introducirse plenamente alguien en un ambiente determinado", o en tercera, acción y efecto de introducir o introducirse en un ámbito real o imaginario, en particular "en el conocimiento de una lengua determinada" (DRAE, 2010). Como suele suceder, el término está lejos de tener una definición clara cuando se utiliza en el contexto de los videojuegos; por una parte la industria y el marketing correspondiente emplean este término para satisfacer sus necesidades promocionales; inmersión o adicción se usan en la publicidad de productos por su capacidad mnemónica, esto es, por su capacidad de ser recordados (Martínez, 2010); en el ámbito académico surgen dudas respecto a qué quiere significar el término inmersión y la necesidad de acotar y definir adecuadamente este concepto.

A la palabra inmersión se le atribuyen distintos significados, con tintes polisémicos y a veces como reclamo vacío. Por lo tanto intentamos perfilar el concepto y ver en qué medida las narrativas pueden intensificar ese fenómeno. En la literatura científica existente encontramos autores que han abordado esta cuestión léxica y conceptual para responder mejor a algunas demandas sociales, como la preocupación y la exigencia legal ante los videojuegos considerados alienantes, violentos o peligrosos para la infancia y la juventud (McMahan, 2003:70).

González Tardón considera a la inmersión como "el tiempo que una persona se integra en una realidad artificial, perdiendo la noción del tiempo y del espacio circundante" (2006); su trabajo tiene que ver con la utilización de avatares como agentes informáticos para la realización de terapias psicológicas; al parecer, como él mismo apunta, el empleo de estos recursos bajo la denominación de chabots, un robot de conversación, no es nueva, sino que se ha venido experimentando con ellos desde los años sesenta, con la particularidad de que las personas atribuyen rápidamente humanidad a la máquina y hablan con ella como si fuera un terapeuta de verdad, es decir, se produce "la inmersión al aceptar el simulador como un ser real e interactuar con él de forma "normalizada" o natural" (González Tardón, 2006), un paso hacia la evidencia de un tipo de inmersión social. 


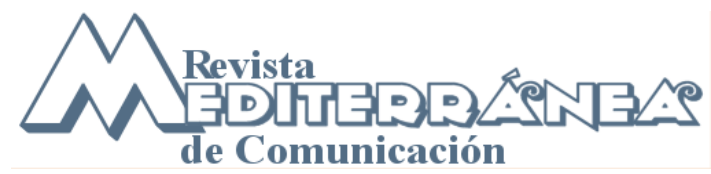

ISSN 1989-872X - Año3 (2012), pp. 1-13

Para Murray (1997) la inmersión representa un término metafórico que se corresponde con una experiencia placentera y participativa, provocada por determinados tipos de narrativas que actúan sobre nuestro cerebro, de manera que éste sintoniza con la historia con tal intensidad que puede hacer olvidar al sujeto el mundo que le rodea. Por su parte McMahan (2003) encuentra varias dificultades en el uso de 'inmersión' para describir procesos y situaciones; es crítica con el empleo polisémico del término y su complejidad le supone desglosar el término y emplear 'presencia' cuando se trate de estudiar los efectos de inmersión situacional, tanto en videojuegos de sobremesa, ordenador o consolas, o en los más indicados para un estudio de este tipo, que serían los propios de la realidad virtual.

Por lo tanto podemos establecer que la inmersión es una experiencia de sustitución de la realidad por un entorno artificial que recorre un eje continuo desde la concentración perceptiva hasta la ilusión perceptiva. Autores como Csikszentmihalyi (1990), Murray (1997), McMahan (2003), han tratado varios conceptos próximos a esta definición.

\subsection{Presencia y flujo}

De Csikzentmihalyi destaca su idea de flux, fluir o flujo, según la cual los jugadores alcanzan un estado al que desean volver porque se encuentran en una situación en el que fluyen con el medio artificial que les envuelve, de manera que se encuentran inmersos, absortos, en esa actividad que les produce una experiencia óptima que puede parecerse a la felicidad como ocurre con los músicos o los jugadores de ajedrez (Csikzentmihalyi, 1990: 81). Precisamente esa componente de felicidad en el concepto de flujo ha sido criticada, pero la descripción se parece mucho a la inmersión que tratamos aquí; además ha servido para conducir importantes investigaciones que van más allá de los videojuegos; sin embargo, flujo e inmersión no son lo mismo, en cuanto que no tiene que ser placentera la experiencia para producir inmersión, como ocurre cuando leemos, o jugamos, una obra trágica angustiosa. Posteriores trabajos sobre el concepto de flujo han servido para dar paso a una doble consideración sobre la inmersión, la inmersión diegética, una forma de inmersión relativamente superficial en el medio, y la inmersión situacional, en la que el jugador se sumerge en el espacio recreado por el videojuego (Pace, 2008), en el que el videojugador pierde la conciencia del entorno real, participa del medio virtual y modifica su sensación de paso del tiempo. Para este autor, la inmersión diegética se sitúa en el acto de jugar un juego, o leer un relato, mientras que la inmersión situacional coloca al jugador en el espacio del juego y le permite interactuar con él, denominándose entonces presencia o telepresencia (Pace, 2008).

Entre las pocas aportaciones y usos de estos conceptos desde las áreas de comunicación, Laura Tapia (2006) recupera la idea de inmersión y flujo, y menciona las ideas de Csikzentmihalyi cuando trata de la producción de videojuegos orientados al entretenimiento avanzado, como Brain Training (2005), en los que se pondrían en acción partes del cerebro que no suelen utilizarse cuando el jugador se dedica a interactuar con juegos convencionales; posteriores estudios acerca del 'marketing científico' de Nintendo evidencian la falta de base de esas suposiciones sobre la gimnasia cerebral, que si bien funciona en unos casos, en otros no.

También se emplea el término 'presencia' próximo al de 'inmersión' que merece algunas aclaraciones; la presencia se describe como la situación en la que el jugador tiene la sensación de que forma parte del mundo del juego, interactúa con él y sus acciones tienen consecuencias sobre ese mundo que le rodea; por lo tanto se debería emplear para describir la inmersión situacional (Tamborini y Skalski, 2006:225). Esta sensación de 
presencia resulta más frecuente en entornos propios de realidad virtual, aunque videojuegos en primera persona también pueden evocar esa sensación.

\title{
3.4. Conexiones entre inmersión y forma audiovisual
}

¿Qué elementos debe incorporar la relación videojuego - jugador para producir la sensación de inmersión situacional? Podemos encontrar claves en la construcción de actividades que pueden producir flujo.

\begin{abstract}
"Lo que hace que estas actividades produzcan flujo es que se diseñaron para hacer más fácil lograr la experiencia óptima. Tienen reglas que requieren un aprendizaje de habilidades, establecen metas, producen retroalimentación, hacen posible el control. Facilitan la concentración y la involucración haciendo que la actividad sea lo más distinta posible de la denominada realidad primordial de la existencia cotidiana" (Csikszentmihalyi, 1996: 116).
\end{abstract}

La adopción del punto de vista central autores, y jugadores, coinciden en que un shooter en primera persona involucra más que otros juegos (Nacke y Lindley, 2008: 81); la observación de la experiencia de juego en jóvenes adolescente también señala que ante un videojuego de fútbol, como Fifa10 (2010), el jugador termina, más pronto que tarde, hablando con la máquina, generalmente para increparla, por lo que los grados de la inmersión aún permanecen inexplorados (Peláez, 2009). Pace (2008) establece las siguientes características que deben darse para provocar en el jugador la sensación de flujo, a saber, metas claras, información continua sobre los progresos, avances o retrocesos del jugador en el juego, equilibrio entre los retos que se plantean y las habilidades del jugador, focalización de la atención, conciencia reducida de los factores irrelevantes del entorno que rodea al jugador; aún así se puede producir la sensación de flujo sin que se produzca el máximo grado de inmersión situacional o 'presencia'.

Dentro de las características estéticas tanto la perspectiva como el realismo constituyen dominios de trabajo experimental; la perspectiva central, a diferencia de la isométrica, implica más al sujeto por sus concomitancias con la perspectiva natural; cuando el punto de vista de la cámara coincide con el del usuario trasforma la representación objetiva del juego en su visión subjetiva como jugador; podemos entender que cuando a esa elección se añaden los movimientos de cámara sincronizados con los movimiento del jugador, la experiencia de navegación sea completa. También influye la interacción con el mundo físico que comienza con el reconocimiento de éste; de ahí la importancia del realismo que puede ser hasta cierto punto relativa, porque se puede evidenciar la ausencia de realismo de las primeras versiones de Doom (1993) o Quake (1996) y al mismo tiempo reconocer su enorme potencial inmersivo; sin embargo, la industria sigue persiguiendo a través de imágenes hiperrealistas reconstrucciones fidedignas de la realidad. Debemos citar la componente sonora de los videojuegos, que juega un papel decisivo y diferencial en la producción de la sensación inmersiva situacional; dentro de los factores externos al juego, las interfaces constituyen un área en constante desarrollo que persigue optimizar la experiencia audiovisual, ya que no es lo mismo jugar en un entorno acústicamente aislado del mundo circundante, en el que solo se oyen los sonidos del juego, utilizando auriculares adecuados, que hacerlo en un entorno abierto a otros estímulos.

En cuanto a la construcción del relato, tanto las narrativas lineales, como las multilineales o las experienciales pueden conducir a la inmersión situacional; ahora bien, las narrativas que lleven a una inmersión social tienen más interés por cuanto los jugadores interactúan con otros avatares o jugadores (Mainer, 2010). Esa sensación inclusiva, de participación o de colaboración, proporciona nuevas posibilidades exploradas en los juegos que ofrecen la 
posibilidad de ser jugados en modo multijugador o en red. La narrativa elegida tendrá que resolver adecuadamente los elementos de interacción que faciliten las relaciones entre los jugadores y el programa de juego.

\section{A modo de conclusiones}

La ausencia de literatura académica en torno a los videojuegos sirve para mostrar la situación del campo en España; poco a poco van apareciendo aportaciones que dan cuenta de un incremento en el interés de las disciplinas de comunicación por los videojuegos. También hemos visto que el término 'inmersión' aparece en el ámbito especializado anglosajón, del que proceden referencias significativas, lo que contrasta con la escasa frecuencia del concepto en las publicaciones académicas españolas.

Hemos expuesto los conceptos de 'vinculación', 'inmersión' y 'presencia' intentando caracterizar estos términos. Hemos visto la importancia de la vinculación y la geometría variable de la inmersión que se mueve en un continuo desde la concentración perceptiva a la ilusión perceptiva de 'presencia', término también conocido como inmersión situacional.

Aunque no hemos podido establecer la existencia de conexiones entre estos términos que caracterizan a los videojuegos, nos parece que ésta puede ser una línea de trabajo interesante. El recorrido que hemos hecho sugiere la necesidad de otras investigaciones que profundicen en las relaciones que existen entre la forma de los videojuegos, su narrativa y los estados descritos aquí.

La velocidad de desarrollo que presentan los videojuegos, la riqueza proteica del fenómeno, junto a la exploración de nuevas narrativas y la evolución de las tecnologías infotelemáticas permiten vislumbrar algunos escenarios futuros de esta industria cultural. Como ha ocurrido con otros medios emergentes, los videojuegos utilizarán recursos y formas de otros campos próximos, al mismo tiempo que trasvasan usuarios desde esos medios al propio. En ese contexto de sustitución de una tecnología analógica, como puede ser el cine convencional, surge un escenario desarrollista para el cine del siglo XXI que tendrá como objetivos destacados obtener la inmersión perceptiva, situacional y social de los usuarios. En la actualidad ya encontramos algunas manifestaciones embrionarias en ese sentido que evolucionan hacia nuevas formas audiovisuales en las que no resulta sencillo distinguir si nos encontramos ante un videojuego o una película.

La investigación académica en comunicación puede contribuir al desarrollo de nuevos productos audiovisuales, recursos e interfaces que promuevan la inmersión por medio de imágenes tridimensionales, sonido envolvente y realidad virtual dónde los usuarios puedan elegir entre diferentes formas de relato. En esos contextos las narrativas lineales 0 multilineales, frecuentes ahora en el cine y en los videojuegos clásicos, darán paso a nuevas narrativas experienciales y sociales; el espectador, convertido en actor, interactuará con entes informáticos, con otros espectadores - actores, y con el entorno que le rodea, transformando el espacio-tiempo de los videojuegos con nuevos relatos colaborativos. Y como saben aquellos que mantienen relación directa con los videojuegos, parte de ese futuro ya está aquí.

\section{Referencias}

Aarseth, E. (2007): "Investigación sobre juegos: aproximaciones metodológicas al análisis de los juegos". Artnodes 7: http://www.uoc.edu/artnodes/7/dt/esp/aarseth.pdf (03.08.2010). 
Alexander, A. et al. (2005): "From gaming to training: A review of studies on fidelity, immersion, presence, and buy-in and their effects on transfer in pc-based simulations and games", recurso en línea, disponible en http://citeseerx.ist.psu.edu (03.08.2010).

Armenteros, Manuel; Fernández, Marta (2010). "Inmersión, presencia y flow". Contratexto 19: http://www.ulima.edu.pe/revistas/contratexto/9.pdf (24.06.2011).

Arroyo Almaraz, I. (1999): "Cine, TV y videojuegos en la mente del niño". Cuadernos de Pedagogía 278, pp. 80 a 85.

Castellana, M. et al. (2007): "El adolescente ante las tecnologías de la información y la comunicación: internet, móvil y videojuegos". Papeles del Psicólogo, v. 28, n. 3, pp. 196 a 204: http://redalyc.uaemex.mx/pdf/778/77828306.pdf (01.08.2010).

Checa Godoy, A. (2009): "Hacia una industria española del videojuego". Comunicación 7, v. 1 , pp.

177-188:

http://www.revistacomunicacion.org/pdf/n7/articulos/a12_Hacia_una_industria_espanola_del _videojuego.pdf (01.12.2010).

Csikszentmihalyi, M. (1996): Fluir (Flow). Una psicología de la felicidad. Barcelona: Kairós. Título original, Flow: The Psychology of Optimal Experience. New York: HarperPerennial, 1990.

De Aguilera, M.; Méndiz, A. (2003): "Video games and education: Education in the Face of a 'Parallel School". ACM Computers in Entertainment 1, v. 1, pp. 1-14.

De Aguilera, M. (2004): "La institucionalización de una industria cultural. Estructura y desafíos de la industria de los videojuegos". Telos 59, http://sociedadinformacion.fundacion.telefonica.com/telos/articuloperspectiva.asp@idarticulo $=3 \& \mathrm{rev}=59$. htm $(01.02 .2011)$.

De Aguilera, M.; Méndiz, A. (2006): "Videojuegos y educación", VV AA, Reflexiones en torno a la libertad de empresa informativa (Ed. Manuel Sevillano Puente). Madrid: Universidad Complutense de Madrid, pp. 135-158.

Díez Gutiérrez, E. (dir.) (2004): La diferencia sexual en el análisis de videojuegos. Madrid: Instituto de la Mujer. CIDE. Ministerio de Educación y Ciencia, ISBN 84-688-9969-0.

Dondlinger, M. (2007): "Educational Video Game Design: A Review of the Literature". Journal of Applied Educational Technology, v. 4, n.1, pp. 21-31.

Garitaonaindía, Carmelo, et al. (1999): “Qué ven y cómo juegan los niños españoles”. Zer 6, pp. 67-97: http://www.ehu.es/zer/zer6/4garita.htm (01.05.2011).

González Tardón, Carlos (2006): “Interacción con seres simulados. Nuevas herramientas en psicología experimental", en VV AA, Una perspectiva de la Inteligencia Artificial en su 50 aniversario (Eds. Fernández-Caballero, A. et al.). Albacete: Universidad de Castilla-La Mancha, pp. 438-449. 


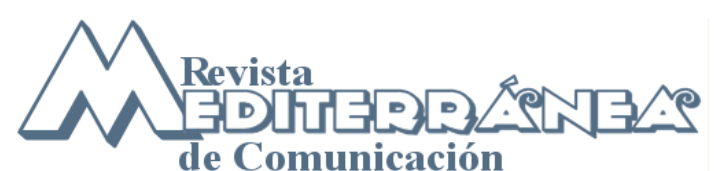

ISSN 1989-872X - Año3 (2012), pp. 1-13

Gramigna, A.; González-Faraco, J. C. (2009): "Videojugando se aprende: renovar la teoría del conocimiento la educación. Comunicar 33, v. XVII, pp. 157-164, http://www.revistacomunicar.com/index.php?contenido=detalles\&numero=33\&articulo $=33$ 2009-19 (26.05.2011).

Gros, B. (1998): Jugando con los videojuegos: educación y entretenimiento. Bilbao: Desclée de Brouwer.

Landwehr, P.; Diesner, J.; Carley, K. M. (2009): "The Words of Warcraft: relational text analysis of quests in a MMORPG". Proceedings DIGRA 2009 Breaking New Ground: Innovation in Games, Play, Practice and Theory: http://www.digra.org/dl/db/09287.34363.pdf (03.05.2011).

Klug, Ch. G.; Schell, J. (2006): "Why people play games: an industry perspective", en VV AA, Playing video games: motives, responses and consequences (Eds. Peter Vonderer y Jennings Bryant). Mahwah NJ: Lawrence Erlbaum, pp. 104-114.

Mainer, B. (2010): "El videojuego, punto central del ocio digital". Espéculo. Revista de Estudios Literarios 45: http://www.ucm.es/info/especulo/numero45/videojue.html (21.05.2011).

Martín, E. (2010): "Videojuegos y publicidad. Cómo alcanzar a las audiencias que escapan de los medios tradicionales". http://sociedadinformacion.fundacion.telefonica.com/DYC/TELOS/ResultadoBsquedaTELOS /DetalleArticuloTelos_82TELOS_DOSSIER5/seccion=1227\&idioma=es_ES\&id=2010020311 250001\&activo $=6$. do $(26.03 .201 \overline{1})$.

McMahan, A. (2003): "Inmersion, Engagement, and Precense: A Method for Analyzing 3-D Video Games", en The Video Game Theory Reader,(Eds. Mark Wolf y Bernard Perron). New York: Routledge, pp. 67-86.

Marcos Molano, M.; Martínez Loné, P. (2006): "La dimensión simbólica del jugador de videojuegos". Icono 14 8:http://www.icono14.net/revista/num8/articulos/02.pdf (21.05.2011).

Moreno, P. M. (2003): "El videojuego: lecciones de la primera cultura multimedia, en VV AA, Hacia un nuevo sistema mundial de la comunicación. Las industrias culturales en la era digital, (Coord. Enrique Bustamante). Barcelona: Gedisa, pp. 207-226.

Murray, J. (1999), Hamlet on the Holodeck: The Future of Narrative in Cyberspace. Cambridge MA: The MIT Press.

Nacke, L.; Lindley, C. (2008): "Flow and Immersion in First-Person Shooters: Measuring the player's gameplay experience”. Future Play 3-5, pp. 81-88.

Pace, S. (2008): "Immersion Flow And The Experiences Of Game Players". SimTecT, Melbourne mayo.

Peláez, B. (2009): "Fútbol y videojuegos. Reiventando el juego". Razón y Palabra 69: http://www.razonypalabra.org.mx (20.06.2011). 


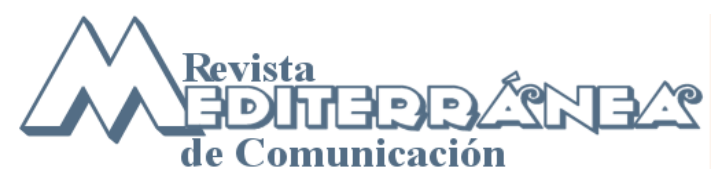

ISSN 1989-872X - Año3 (2012), pp. 1-13

Pestano, J.; Gabino, M. (2010): "La experiencia de inmersión en el espacio tiempo de los videojuegos". II Encuentro internacional de narrativas audiovisuales, México, julio.

Pestano, J.; Von Sprecher, R.; Trenta, M. (2010): "Cómics y videojuegos, dos industrias en conexión".

Área Abierta,

25:

http://revistas.ucm.es/inf/15788393/articulos/ARAB1010130004A.PDF (01.06.2011).

Rosas, R. et al. (2003): "Beyond Nintendo: design and assessment of educational video games for first and second grade students". Computers \& Education 1, v. 40, pp. 71-94.

Rodríguez Breijo, V.; Pestano, J.; Fuster García, F. (2011): "Empresa y producción de videojuegos en España". Actas IV Congreso Internacional de Análisis Fílmico, Castellón, mayo.

Sáez Soro, E. (2009): "Videojuegos de universos persistentes: la comunicación en la construcción de una vida virtual". Comunicación 7, pp. 205-221.

Siabra Fraile, J. (2009): "Los géneros de videojuegos como géneros de mundos virtuales". Eikasia. Revista de Filosofía 24, v. IV: www.revistadefilosofia.org (20.06.2011).

Sicart, M. (2007): "Vivir mil vidas: narrativa y diseño de juegos de ordenador". Curso de verano Comunicación Interactiva y Convergencia Hipermedia. Facultad de Comunicación. Universidad de Santiago de Compostela, julio.

Tapia Meléndez, L. (2006): "Estimulación y relax mental a través del uso de videopasatiempos de última generación: Nintendo DS y The Touch Generations". Icono14 8: http://www.icono14.net/revista/num8/articulos/07.pdf (01.05.2011).

Tamborini, R.; Skalski, P. (2006): "The Role of Presence in Experience of Electronic Games", en VV AA, Playing video games: motives, responses, and consequences (Eds. Peter Vorderer y Jennings Bryant). Mahwah NJ: Lawrence Erlbaum. 